\title{
A Solution to Optimal Power Flow Problem using Artificial Bee Colony Algorithm Incorporating FACTS device
}

\author{
T L V Naga Lathish ${ }^{1}$, A.V.Naresh Babu ${ }^{2}$, S.Sivanagaraju ${ }^{3}$ \\ ${ }^{I}$ (PG Student [P.E], Dept. of EEE, DVR \& Dr. HS MIC College of Technology, Andhra Pradesh, India) \\ ${ }^{2}$ (Associate Professor, Dept. of EEE, DVR \& Dr. HS MIC College of Technology, Andhra Pradesh, India) \\ 3 (Professor, Dept. of EEE, University College of Engineering, JNTUK, Kakinada, Andhra Pradesh, India)
}

\begin{abstract}
This paper presents an intelligent foraging behaviour based optimization approach i.e. artificial bee colony $(A B C)$ algorithm for achieving the optimal power flow $(O P F)$ problem solution incorporating the flexible alternating current transmission system (FACTS) device which is static synchronous series compensator (SSSC). The SSSC consists of a solid-state voltage source converter with gate turn off (GTO) device, a dc link capacitor, a magnetic circuit and a controller. The injected voltage is in quadrature with the line current and emulates an inductive or a capacitive reactance so as to influence the power flow in the transmission lines. The effectiveness of the approach has been tested on IEEE 14-bus system with and without SSSC. Results show that the ABC algorithm gives better solution to enhance the system performance with SSSC compared to without SSSC.
\end{abstract}

Keywords: Artificial Bee Colony Algorithm, Foraging Behaviour, Optimal Power Flow, Power Loss, SSSC.

\section{INTRODUCTION}

The electric power industry over the worldwide becoming complex day to day and continuous requirements are coming for stable, secured, controlled, economic and better quality power. These requirements become more essential when environment becoming more vital and important deregulation. Power transfer capacity in transmission system is limited due to various factors such as steady state stability limit, thermal limit, transient stability limit and system damping or even negative damping. The transmission system become increasingly subject several constraints and difficulties to operate. To meet these requirements number of applications linked with FACTS devices has been increased in recent years. A.Edris et.al. [1] defined FACTS is a system composed of static equipment used for the AC transmission of electrical energy. It is meant to enhance controllability and increase power transfer capability of the network. It is generally a power electronics based system. FACTS technology [2] provides feasible and cost-effective solution to these problems and these devices are required to use worldwide for improving performance of power system [3].

Recently, several FACTS devices have been implemented and installed in practical power systems such as static VAR compensator (SVC), thyristor controlled series capacitor (TCSC), and thyristor controlled phase shifter (TCPS) [4]. Some FACTS devices which operates based on the synchronous voltage source (SVS) include the SSSC [5] and the unified power flow controller (UPFC) [6]. The SSSC provides a compensating voltage over both a capacitive and inductive range irrespective of the line current. The magnitude and phase of this inserted ac compensating voltage can be rapidly adjusted by SSSC controls.

Several population-based methods have been proposed for solving the OPF problem successfully such as evolutionary algorithms [7] and swarm intelligence-based algorithms [8]. Although genetic algorithm (GA) [9], genetic programming (GP) [10], evolution strategy (ES) and evolutionary programming (EP) [11] are popular evolutionary algorithms, GA is the most widely used one in the literature. GA is based on genetic science and natural selection and it attempts to simulate the phenomenon of natural evolution at genotype level while ES and EP simulate the phenomenon of natural evolution at phenotype level. One of the evolutionary algorithms which have been introduced recently is differential evolution (DE) algorithm. A popular swarmintelligence-based algorithm is the particle swarm optimization (PSO) algorithm which was introduced by Eberhart and Kennedy in 1995 [12]. A.V.Naresh Babu and S.Sivanagaraju [13] proposed a new approach based on two step initialization to solve the OPF problem. Methods to find the solution for OPF problem have been discussed in [14, 15]. The ABC algorithm [16, 17] is a new metaheuristic, population-based optimization technique inspired by the intelligent foraging behavior of the honeybee swarm. The OPF problem was formulated as an optimization problem and solved using $\mathrm{ABC}$ algorithm. The objective function is to minimize the fuel cost. A load flow model is used i.e. newton-rapson (NR) method. This model is further modified to incorporate SSSC into the network and ABC technique is applied to the model to enhance the performance of the power system. The effectiveness of the method was tested on standard IEEE 14-bus test system and the results are presented. 


\section{STATIC SYNCHRONOUS SERIES COMPENSATOR}

The voltage source converter based series compensator, called static synchronous series compensator was proposed by Gyugyi in 1989. An SSSC comprises of voltage source converter, capacitor and a coupling transformer that is used to insert the ac output voltage of the inverter in series with the transmission line. This is equivalent to providing controllable capacitive or inductive reactance compensation independent of the line current. The magnitude and phase of this inserted ac compensating voltage can be rapidly adjusted by the SSSC controls [18]. The VSC is triggered by the SSSC control which itself receives setpoint values. The VSC is protected against unacceptable high fault currents by a mechanical bypass which can be closed if necessary. In this way, the SSSC controls the power flow of the transmission line or the voltage of the bus.

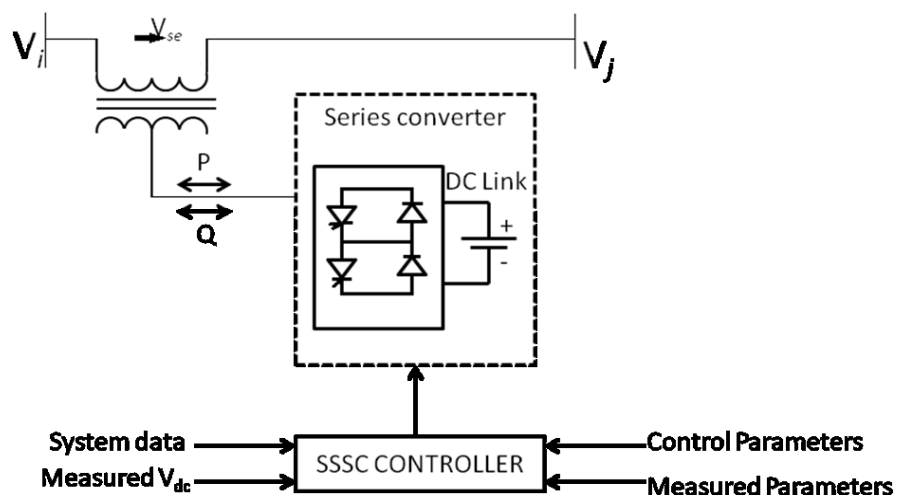

Fig. 1 Schematic diagram of SSSC

\section{MATHEMATICAL FORMULATION OF OPF WITH SSSC}

Mathematically, the OPF problem with FACTS to minimize fuel cost generation is solved by maintaining thermal and voltage constraints can be formulated as follows

$$
\text { Minimize } \quad \sum_{l=1}^{x g e n}\left(a_{l} P_{\text {genl }}^{2}+b_{l} P_{\text {genl }}+c_{l}\right) \$ / h
$$

where $a_{l}, \quad b_{l}, \quad c_{l}$ are cost co-efficient of generator at bus $l$

xgen is the number of generator buses.

Power flow equalities in the optimal power flow are given as follows

$$
\begin{gathered}
\text { Pgen }_{l}-\text { Pdem }_{l}-\sum_{m=1}^{x b}\left|V_{l}\right|\left|V_{m}\right|\left|Y_{l m}\right| \cos \left(\theta_{l m}-\delta_{l}+\delta_{m}\right)+P_{i n j, n}=0 \\
\text { Qgen }_{l}-\text { Qdem }_{l}+\sum_{m=1}^{x b}\left|V_{l}\right|\left|V_{m} \| Y_{l m}\right| \sin \left(\theta_{l m}-\delta_{l}+\delta_{m}\right)+Q_{i n j, n}=0
\end{gathered}
$$

Pgen $_{l}$ and Qgen $_{l}$ is the active and reactive power of generation at bus $l$,

Pdem $_{l}$ and Qdem $_{l}$ is the active and reactive load demand at the same bus, and elements of the bus admittance matrix are represented by $Y_{l m}$ and $\theta_{l m}$ is the angle difference of transmission line connected between $l \& m$ buses.

Active power outputs, reactive power outputs, and generation bus voltages are restricted by their lower and upper limits and the generator constraints are given as follows

$$
\begin{aligned}
& \text { Pgen }_{l}{ }^{\text {in }} \leq \text { Pgen }_{l} \leq \text { Pgen }_{l}{ }^{\text {max }} \quad l=1,2,3, . . \text {, xgen } \\
& \text { Qgen }_{l}{ }^{\text {min }} \leq \text { Qgen }_{l} \leq \text { Qgen }_{l}{ }^{\text {max }} \quad l=1,2,3, . ., \text { xgen } \\
& V_{l}^{\min } \leq V_{l} \leq V_{l}^{\max } \quad l=1,2,3, . ., x b
\end{aligned}
$$

$x b$ is the number of buses

Transformer tap settings are restricted by their lower and upper limits and the transformer constraints are given as follows

$$
T_{l}^{\min } \leq T_{l} \leq T_{l}^{\max } \quad l=1,2,3, . ., x t
$$

$x t$ is the number of transformers. 
Shunt VAR compensations due to capacitor banks are restricted by their limits and the shunt VAR constraints are given as follows

$$
Q \operatorname{var}_{l}^{\text {min }} \leq Q \operatorname{var}_{l} \leq Q \operatorname{var}_{l}^{\text {max }} \quad l=1,2,3, . ., x \text { var }
$$

$x$ var is the number of shunt VAR compensators.

SSSC device constraints are restricted by their limits as follows

$$
\begin{aligned}
& V_{\text {ser }}{ }^{\text {min }} \leq V_{\text {ser }} \leq V_{\text {ser }}{ }^{\text {max }} \\
& \text { Aser }^{\text {min }} \leq \theta_{\text {ser }} \leq \theta_{\text {ser }}{ }^{\text {max }}
\end{aligned}
$$

$V$ ser and $\theta$ ser are the Series voltage source magnitude and Series voltage source angle respectively. The load of $l^{\text {th }}$ transmission line is restricted by its limits are given as follows

$$
S_{t l} \leq S_{t l}^{\max } \quad t l=1,2,3, . ., x t l
$$

$x t l$ is the number of transmission lines.

\section{ARTIFICIAL BEE COLONY ALGORITHM}

The Artificial Bee Colony algorithm proposed by Dervis Karaboga in 2005 for real-parameter optimization is a recently introduced optimization algorithm which simulates the foraging behaviour of bee colony. In the $\mathrm{ABC}$ algorithm, the foraging artificial bees are divided into three groups: employed bees, unemployed bees and scout bees. One half of the colony size of the $\mathrm{ABC}$ algorithm represents the number of employed bees, and the second half stands for the number of unemployed bees. The employed bees are responsible for exploiting the explored food sources and passing their food information to onlooker bees. The onlooker bees will make a move to choose a food source on this information, and then further exploit the foods around the chosen food source. The employed bee change to a scout bee when it abandons a food source and search the environment surrounding the nest (up to a $14 \mathrm{~km}$ radius) for the new food sources. The details of the algorithm are as follows

\subsection{Food source sites initialization}

In the initialization of the algorithm, a set of food source sites $(e b)$ are created randomly. Let's consider $u^{\text {th }}$ food source in the population as

$$
d_{u}=d_{u, 1}, d_{u, 2}, d_{u, 3}, \ldots, d_{u, n}
$$

And each food source site is created as per the Eq. (13)

$$
d_{u, v}=d_{u}{ }^{\min }+\operatorname{rand}(0,1)\left(d_{u}{ }^{\max }-d_{u}{ }^{\min }\right)
$$

Where $u$ signifies the size of food source sites, $u=1,2,3 \ldots e b, v$ signifies the parameters to be optimized, $v=1,2,3, \ldots, n c v, d_{u}{ }^{\max } \& d_{u}{ }^{\min }$ are the upper and lower bounds for the dimension $u$. After initialization of the food source sites $f i t_{u}$ amounts are calculated.

\subsection{Employed bee forager}

A new candidate food sources is created by modification of $d_{u}$ of its current position and then calculate nectar or $f i t_{u}$ amount. The position of the new food source is defined as

$$
w_{u, v}=d_{u, v}+\xi_{u, v}\left(d_{u, v}-d_{q, v}\right)
$$

Where $q=1,2,3, \ldots, e b$ is a randomly chosen index that has to be different from $u, \xi_{u, v}$ is a uniformly distributed real random number in the range $[-1,1]$.

$$
\text { fit }_{u}= \begin{cases}\frac{1}{1+o b j_{u}} & \text { if } o b j_{u} \geq 0 \\ 1+a b s\left(o b j_{u}\right) & \text { if } o b j_{u}<0\end{cases}
$$

Where $o b j_{u}$ is the cost value or objective value of the solution $w_{u}$. If the $f i t_{u}$ of $w_{u}$ is equal or better than that of $d_{u}$, it will be replaced by the new candidate food source position $w_{u}$, otherwise the previous position is kept in memory. 


\subsection{Onlooker probabilities}

After all employed bees complete the search process, each onlooker bee chooses a food source. The probability that a food source will be chosen by the onlooker bee is calculated by the following expression

$$
\operatorname{prob}_{u}=\frac{f i t_{u}}{\sum_{u=1}^{e b} f i t_{u}}
$$

\subsection{Onlooker bee forager}

This is also similar to employed bee forager step. Here, candidate food source is created of its current position as per Eq. (14) and calculate fit $_{u}$ value. If the new candidate food source has equal or better fit $_{u}$ value than the old source, it is replaced with the old one in the memory. Otherwise, the old one is retained in the memory. This process is repeated until all onlookers are distributed onto food source sites.

\subsection{Scout bee forager}

If the $f_{i t}$ value of the employed bees does not improved by a continuous predetermined number of iterations, those food sources are abandoned. The food source abandoned by its bee is replaced with a new food source discovered by the scout as per Eq. (13)

\section{RESULTS AND DISCUSSIONS}

Simulation studies are carried out in this section to investigate the effects of the SSSC on the power system. The method is implemented using MATLAB software package on a personal computer with Intel Pentium dual core $2.6 \mathrm{GHz}$ processor and $2 \mathrm{~GB}$ RAM. The ABC algorithm is employed to solve OPF problem by incorporating SSSC for enhancement of system performance. The ABC parameters used for the simulation are summarized in Table 1.

Table 1 ABC parameters

\begin{tabular}{|c|l|l|}
\hline S.No & Control variables of ABC algorithm & values \\
\hline 1 & Swarm size & 20 \\
\hline 2 & Number of employed bees foragers & $50 \%$ of swarm size \\
\hline 3 & Number of onlooker bees foragers & $50 \%$ of swarm size \\
\hline 4 & Number of iterations & 10 \\
\hline 5 & Number of scouts per cycle & 1 \\
\hline
\end{tabular}

Table 2 Optimal settings of control variables for IEEE-14 Bus test system

\begin{tabular}{|c|c|c|c|}
\hline S.No & Parameters & Case 1 & Case 2 \\
\hline 1 & $\mathrm{P}_{\mathrm{g} 1}$ & 74.015 & 82.213 \\
\hline 2 & $\mathrm{P}_{\mathrm{g} 2}$ & 113.467 & 93.966 \\
\hline 3 & $\mathrm{P}_{\mathrm{g} 3}$ & 27.634 & 36.403 \\
\hline 4 & $\mathrm{P}_{\mathrm{g} 6}$ & 37.317 & 40.109 \\
\hline 5 & $\mathrm{P}_{\mathrm{g} 8}$ & 11.448 & 10.963 \\
\hline 6 & $\mathrm{~V}_{\mathrm{g} 1}$ & 1.050 & 1.058 \\
\hline 7 & $\mathrm{~V}_{\mathrm{g} 2}$ & 1.037 & 1.018 \\
\hline 8 & $\mathrm{~V}_{\mathrm{g} 3}$ & 1.023 \\
\hline 9 & $\mathrm{~V}_{\mathrm{g} 6}$ & 1.023 & 1.024 \\
\hline 10 & $\mathrm{~V}_{\mathrm{g} 8}$ & 0.995 & 1.002 \\
\hline 11 & $\mathrm{~T}_{1}$ & 1.023 & 0.926 \\
\hline 12 & $\mathrm{~T}_{2}$ & 1.007 & 0.994 \\
\hline 13 & $\mathrm{~T}_{3}$ & 0.918 & 3.274 \\
\hline 14 & $\mathrm{Q}_{\mathrm{C} 1}$ & 1.037 & 263.654 \\
\hline 15 & Total real power generation & 2.63 & 917.392 \\
\hline 16 & Total Cost & 263.881 & 4.654 \\
\hline 17 & Real power loss & 927.300 & 0.095 \\
\hline 18 & $\mathrm{~V}_{\mathrm{se}}(\mathrm{p} . \mathrm{u})$ & 4.881 & 91.312 \\
\hline 19 & $\theta_{\mathrm{se}}(\mathrm{deg})$ & - & - \\
\hline
\end{tabular}

Table 3 Bus voltages of IEEE-14 Bus system

\begin{tabular}{|c|c|c|c|c|}
\hline \multirow{2}{*}{$\begin{array}{c}\text { Bus } \\
\text { No. }\end{array}$} & $\begin{array}{c}|c| \\
\text { Coltage magnitude } \\
\text { (p.u) }\end{array}$ & $\begin{array}{c}\text { Voltage } \\
\text { angle } \\
\text { (deg.) }\end{array}$ & $\begin{array}{c}\text { Coltage magnitude } \\
\text { (p.u) }\end{array}$ & $\begin{array}{c}\text { Voltage angle } \\
\text { (deg.) }\end{array}$ \\
\hline 1 & 1.050 & 0.000 & 1.064 & 0.000 \\
\hline 2 & 1.037 & -1.341 & 1.058 & -1.131 \\
\hline 3 & 1.023 & -6.568 & 1.018 & -6.437 \\
\hline 4 & 1.001 & -5.104 & 1.026 & -5.004 \\
\hline
\end{tabular}




\begin{tabular}{|c|c|c|c|c|}
\hline 5 & 1.016 & -4.048 & 1.038 & -4.062 \\
\hline 6 & 0.995 & -5.735 & 1.023 & -6.062 \\
\hline 7 & 1.005 & -6.801 & 1.015 & -6.644 \\
\hline 8 & 1.023 & -5.725 & 1.024 & -5.532 \\
\hline 9 & 0.993 & -8.399 & 1.007 & -8.225 \\
\hline 10 & 0.985 & -8.268 & 1.002 & -8.158 \\
\hline 11 & 0.986 & -7.178 & 1.008 & -7.094 \\
\hline 12 & 0.979 & -6.850 & 1.008 & -7.094 \\
\hline 13 & 0.974 & -7.081 & 1.002 & -7.280 \\
\hline 14 & 0.969 & -8.959 & 0.986 & -8.917 \\
\hline
\end{tabular}

The network and load data for this system is taken from [19]. To test the ability of the ABC algorithm one objective function is considered that is minimization of cost of generation. In order to show the effect of power flow control capability of the SSSC in ABC OPF algorithm, two case studies are carried out on the standard IEEE 14-bus system.

Case 1: OPF without SSSC, Case 2: OPF with SSSC.

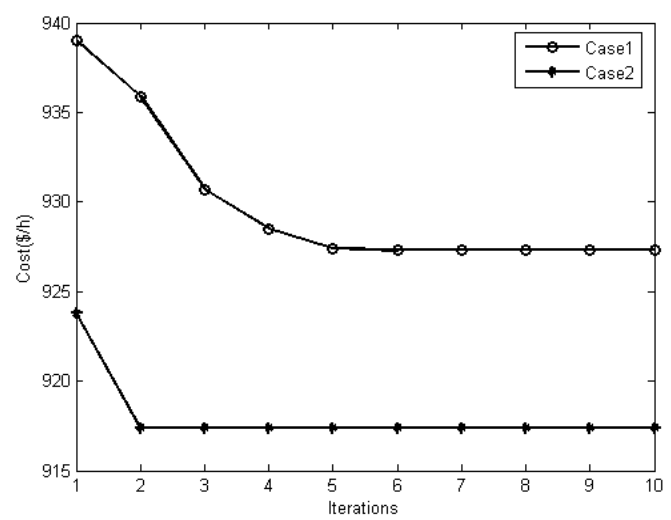

Fig. 2 Cost vs. iterations of IEEE 14 bus system

From the Table 2 and Table 3, it can be seen that the installation of SSSC in the network gives the good performance of the system in terms of reduction in cost of generation, power loss reduction and better voltages. It also gives that $\mathrm{ABC}$ algorithm is able to enhance the system performance while maintaining all control variables and reactive power outputs within their limits. The convergence characteristics with and without SSSC by using $\mathrm{ABC}$ algorithm is shown in Fig 2. From the characteristics it can be seen that the convergence tendency is better with SSSC compared to without SSSC.

\section{CONCLUSION}

This paper incorporates the SSSC in OPF problem to minimize the fuel cost of generation and enhance the system performance. The ABC algorithm is used for solving the OPF problem. The OPF problem is formulated as a nonlinear optimization problem with equality and inequality constraints. The results of the $\mathrm{ABC}$ algorithm were compared with and without SSSC. Among the two test cases, test case 2 had the less fuel cost of generation, power loss reduction as well as voltage improvements. The convergence tendency of the ABC algorithm shows that the algorithm relatively converges in less number of cycles.

\section{REFERENCES}

[1]. A. Edris, R. Adapa, M.H. Baker, L. Bohmann, K. Clark, K. Habashi, L Gyugyi, J. Lemay, A.S. Mehraban, A.K. Myers, J. Reeve, F. Sener, D.R.Torgerson, R.R. Wood, Proposed Terms and Definitions for Flexible AC Transmission System (FACTS), IEEE Trans Power Delivery, Vol. 12, No.4, pp. 1848-1853, Oct. 1997.

[2]. N. G. Hingorani, L. Gyugyi, Understanding FACTS: Concepts and Technology of Flexible AC Transmission Systems, (IEEE Press, New-York, 2000).

[3]. R.M. Mathur and R.K. Varma, Thyristor-Based FACTS Controllers for Electrical Transmission Systems, (IEEE Press and Wiley Interscience, New York, USA, Feb. 2002).

[4]. M. A. Abido and Y. L. Abdel-Magid, Analysis and Design of Power System Stabilizers and FACTS Based Stabilizers Using Genetic Algorithms, 14th Power Systems Computation Conference PSCC2002, Session 14, Paper 4, Seville, Spain, June 24-28, 2002, CD-ROM.

[5]. L. Gyugyi, C.D. Schauder, K.K. Sen, Static Synchronous Series Compensator: A Solid-State Approach to the Series Compensation of Transmission Lines, IEEE Transactions on Power Delivery, Vol. 12, No. 1, Jan. 1997.

[6]. L. Gyugyi, C.D. Schauder, S.L. Williams, T.R. Rietman, D.R. Torgerson, A. Edris, The Unified Power Flow Controller: A New Approach to Power Transmission Control, IEEE Transactions on Power Delivery, Vol. 10, No. 2, Apr. 1995.

[7]. A.E. Eiben, J.E. Smith, Introduction to Evolutionary Computing, Springer, 2003.

[8]. R.C. Eberhart, Y. Shi, J. Kennedy, Swarm Intelligence, Morgan Kaufmann, 2001. 
[9]. J.H. Holland, Adaptation in Natural and Artificial Systems, University of Michigan Press, Ann Arbor, MI, 1975.

[10]. J.R. Koza, Genetic programming: a paradigm for genetically breeding populations of computer programs to solve problems, Technical Report STAN-CS- 90-1314, Stanford University Computer Science Department, 1990.

[11]. L.J. Fogel, A.J. Owens, M.J. Walsh, Artificial Intelligence through Simulated Evolution (John Wiley \& Son, New York, NY, 1966).

[12]. Abido MA. Optimal power flow using particle swarm optimization, Electr Power Energy Syst, Vol.24, pp.563-71, 2002.

[13]. A.V.Naresh Babu and S.Sivanagaraju, A solution to the optimal power flow problem: A new approach based on two step initialization, Proc. of IEEE India International Conference (INDICON) on Engineering Sustainable Solutions, BITS, Hyderabad, India, Dec. 2011.

[14]. Claudio Cañizares, William Rosehart, Alberto Berizzi, Cristian Bovo, Comparison of Voltage Security Constrained Optimal Power Flow Techniques, Proc. 2001 IEEE-PES Summer Meeting, Vancouver, BC, July 2001.

[15]. Florin Capitanescu, Mevludin Glavic, Damien Ernst, Louis Wehenkel, Interior-point based algorithms for the solution of optimal power flow problems, Electric Power Systems Research Vol. 77 (2007) 508-517

[16]. Kursat Ayan, Ulas Kilic, Artificial Bee Colony algorithm Solution for Optimal reactive Power flow, Applied soft computing Vol. $12(2012) 1477-1482$

[17]. Fahad S. Abu-Mouti, M. E. El-Hawary, Optimal Distributed Generation Allocation and Sizing in Distribution Systems via Artificial Bee Colony Algorithm, IEEE Transactions on Power Delivery, Vol. 26, No. 4, Oct 2011

[18]. A.V.Naresh Babu, S.Sivanagaraju and T.Ramana, Mathematical modelling, analysis and effects of static synchronous series compensator (SSSC) parameters in power flow studies, Proc. of Int. Conf. on Machine Intelligence Application to Power Signal Processing Communication and Control (MIPSCCON), GMRIT, Rajam, Andhra Pradesh, India, April 2011.

[19]. IEEE 14-bus system data available at http://www.ee.washington.edu/research/pstca 